
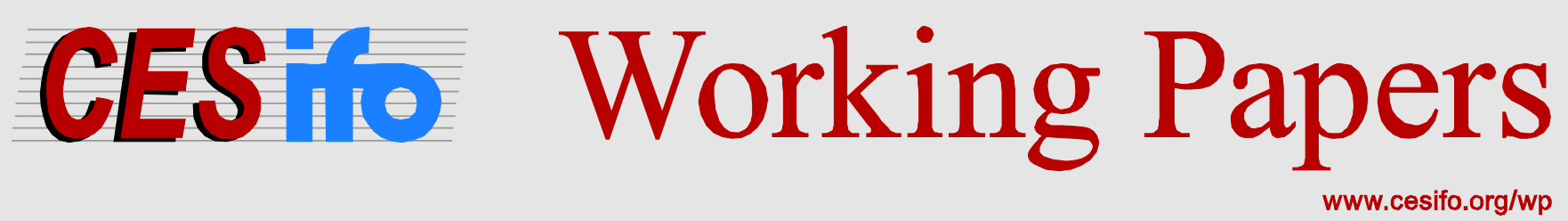

\title{
Airline Fuel Usage and Carbon Emissions: Determining Factors
}

\author{
Jan K. Brueckner \\ Chrystyane Abreu
}

\author{
CESIFO WORKING PAPER NO. 6033 \\ CATEGORY 10: ENERGY AND CLIMATE ECONOMICS \\ August 2016
}

An electronic version of the paper may be downloaded

- from the SSRN website:

- from the RePEc website:

- from the CESifo website:

www.SSRN.com

Www.RePEc.org

www.CESifo-group.org/wp 


\title{
Airline Fuel Usage and Carbon Emissions: Determining Factors
}

\begin{abstract}
Using annual data on individual US airlines over the 1995-2015 period, this paper presents regression results relating an airline's total fuel usage to seven variables: the available ton miles of capacity (passengers plus freight and mail) provided by the airline; the average seat capacity of its aircraft, average stage length (flight distance); average load factor (measured by weight); the average vintage (construction year) of its aircraft; the percentage of the airline's flights that are delayed; and the average annual fuel price. The results show how fuel usage and carbon emissions depend on a small set of crucial variables. The estimated fuel-price effect allows the emissions impact of an optimal emissions charge to be computed, and the estimated delay effect shows the emissions impact of an industry-wide reduction in flight delays. The regression model is generated from a theoretical framework.
\end{abstract}

JEL-Codes: Q500.

Keywords: airline, emissions, emissions charges, carbon.

Jan K. Brueckner Department of Economics University of California, Irvine 3151 Social Science Plaza

USA - Irvine, CA 92697

jkbrueck@uci.edu
Chrystyane Abreu

Department of Industrial Engineering

Federal University of Rio de Janeiro

Cidade Universitaria - Centro de

Tecnologia, Bloco F, sala 108

Brazil - 21941-972 Rio de Janeiro

chrysgerth@gmail.com

June 2016 


\title{
Airline Fuel Usage and Carbon Emissions: Determining Factors
}

by

\author{
Jan K. Brueckner and Chrystyane Abreu*
}

\section{Introduction}

Amid growing concerns about climate change, the airline industry's carbon emissions have gained increasing attention. The industry's $\mathrm{CO}_{2}$ contribution is not very large, accounting for around 2.5\% of total $\mathrm{CO}_{2}$ emissions as of 2006 (Kwan and Rutherford (2015)), but the impact per kilogram of its high-altitude emissions on climate change is about double that of ground-level emissions, as explained by Lee, Lukachko and Waitz (2004). Recognizing the importance of airline emissions, the European Union in 2012 formulated a controversial plan to require all airlines serving EU airports to pay emissions charges under its emissions trading system (ETS). But in the face of substantial opposition, this plan was never fully implemented, with the charges currently limited to Europe's own airlines (see Albers, Buhne and Peters (2009), and Scheelhasse and Grimme (2007)). While the UN's International Civil Aviation Organization was expected to design its own global system of emissions charges, the ICAO instead recently proposed an explicit fuel efficiency standard for new aircraft, intended to take effect in 2028 (Mouawad and Davenport (2016)). Since such a standard would affect airline emissions only gradually, to the disappointment of environmental groups, pressure for some form of international emission charges may persist (Mooney (2016)).

Given the new focus on airline emissions, it is important to gain a better understanding of the link between the emissions volumes of individual airlines and the characteristics of their fleets and flight operations. Since emissions are approximately proportional to fuel consumption, this link can be studied by exploring the connection between an airline's total

fuel usage and its characteristics. The present paper carries out such an exploration. Using annual data on individual US airlines over the 1995-2015 period, the paper presents regression results relating an airline's total fuel usage to seven variables: the available ton miles of capacity (passengers plus freight and mail) provided by the airline; the average seat capacity of 
its aircraft, average stage length (flight distance); average load factor (measured by weight); the average vintage (construction year) of its aircraft; the percentage of the airline's flights that are delayed; and the average annual fuel price. The regression model containing these variables is generated from a theoretical framework, which has elements in common with the earlier model of Brueckner and Zhang (2010). ${ }^{1}$

The results give answers to the following questions: How would an airline's fuel usage (and thus emissions) respond to modernization of its fleet? To the use of larger aircraft? To a shift to longer flights? To a reduction in flight delays? To fuller planes? In addition, the estimated effect of the fuel price on fuel usage captures the impact of greater fuel-conservation effort, holding fixed the characteristics of the airline's fleet and route structure. While the fuel price effect thus only captures short-run usage adjustments, its magnitude can be used to predict the short-run impact of airline emission charges, an exercise that is carried out in the paper.

The linkages between fuel usage (or, more generally, operating costs) and an airline's fleet and operating characteristics have been the focus of a variety of papers, including Kwan and Rutherford (2015), Lee, Lukachko, Waitz and Schafer (2001), Lee, Lukachko, Waitz (2004), Miyoshi and Mason (2009), Morrell (2009), Ryerson and Hansen (2013), Swan and Adler (2006), and Zou, Elke, Hansen and Kafle (2014). The present paper differs from much of this work by focusing on fuel usage (or costs) at the overall airline level rather than the level of individual aircraft. Compared to papers such as Zou et al. (2014) that have an airline-level focus, the present work includes a more comprehensive set of explanatory variables. ${ }^{2}$ The goal is to produce a full picture of the determinants of airline fuel usage, which will help in understanding the industry's carbon emissions and contribution to climate change.

The plan of the paper is as follows. Section 2 presents the conceptual framework, which motivates the empirical model. Sections 3 and 4 present the empirical model and discuss the data and empirical results, and Section 5 offers conclusions.

\section{Conceptual Framework}

\subsection{The setup}

This section of the paper develops the conceptual framework underlying the subsequent 
empirical model. The goal is to identify the determinants of an airline's fuel usage and carbon emissions from a theoretical point of view. To begin, let $A$ denote available seat miles for the airline, more commonly written as ASM. In addition, let $F$ denote fuel usage per available seat mile. Then, total fuel usage by the airline equals $A F$, the product of ASM and fuel usage per ASM, and carbon emissions are proportional to $A F$. Recognizing that airlines carry both passengers and freight, the empirical model measures airline capacity in ton miles rather than seat miles, but for simplicity, the theory is developed using seat miles. ${ }^{3}$

$F$, fuel usage per ASM, is assumed to depend on five factors:

$$
\begin{aligned}
e & =\text { a measure of aircraft fuel efficiency } \\
s & =\text { seats per aircraft } \\
d & =\text { stage length } \\
\ell & =\text { load factor } \\
v & =\text { fuel-conservation effort }
\end{aligned}
$$

Therefore, fuel usage per ASM can be written as $F(e, s, d, \ell, v)$. While, in reality, all these variables are flight-specific, the analysis will instead assume that their values are uniform across the airline's flights. In other words, the airline is assumed to use aircraft of a common size and fuel efficiency operated over a common stage length at a uniform load factor. The empirical framework dispenses with this assumption, replacing the theoretically uniform values of these variables with the average values pertaining to each airline.

The direction of the impacts on fuel usage of the variables are indicated as follows:

$$
\begin{array}{r}
---+- \\
F(e, s, d, \ell, v)
\end{array}
$$

Since greater fuel efficiency and more conservation effort reduce fuel consumption, $F$ is obviously decreasing in $e$ and $v$. In addition, a higher load factor $\ell$ raises fuel use per ASM since the weight of loaded aircraft rises when more seats are filled. Therefore, $F_{e}, F_{v}<0$ and $F_{\ell}>0$ hold, where subscripts denote partial derivatives. As established in a variety of different studies, larger aircraft use less fuel per seat mile than smaller planes, so that $F_{s}<0$ 
holds (see Morell (2009) and Zou et al. (2014)). Two offsetting factors govern the effect of stage length on fuel usage per seat mile. On the one hand, the greater share of cruise miles for a long flight (relative to the flight's fuel-intensive takeoff and climbing portions) tends to reduce fuel usage. On the other hand, the need to carry more fuel on a long flight tends, by raising weight, to increase fuel use per ASM on such flights. Diagrammatic evidence in Lee, Lukachko and Waitz (2004) shows that the first beneficial effect strongly dominates up to stage lengths of around 2000-3000 km, with fuel use per ASM rising modestly thereafter. Miyoshi and Mason (2009) present a similar diagram, which shows carbon emissions (rather than fuel use) per RPM falling up to stage lengths as long as $6000 \mathrm{~km}$. The stage-length effect thus appears to be negative on average, so that $F_{d}<0 .{ }^{4}$

Note that fuel-conserving effort, as captured by $v$, can consist of a variety of possible steps. Such efforts could include reducing the amount of reserve fuel carried per flight to limit weight (Ryerson, Hansen, Hao and Seelhorts (2015); Hao, Hansen and Ryerson (2016)), taxiing on a single engine to reduce ground fuel usage (Hao, Myerson, Kang and Hansen (2016)), and installation of fuel-saving winglets on older aircraft. Observe that, from an empirical perspective, these choices are largely unobservable, not being captured in the available data.

The contribution of airport congestion and flight delays to fuel usage has been ignored so far, and additional steps are needed to include it. A flight delay can raise fuel consumption by increasing taxi time or adding air time at the end of a flight, effects that are independent of stage length. ${ }^{5}$ To capture these congestion effects, let $y$ denote minutes of delay per flight. Suppose that delay-related fuel use depends on $y$ along with aircraft size $s$ and fuel efficiency e. Delay-related fuel usage per flight can then be written as $G(y, s, e)$, with $G_{y}, G_{s}>0$ and $G_{e}<0$.

Total delay-related fuel usage is equal to $G$ times the number of flights. To derive this number, observe that ASM satisties $A=n f s d$, where $n$ is the number of aircraft operated and $f$ equals flights per aircraft. Total flights are thus $n f$, and multiplying by seats per flight and stage length then yields ASM. Delay-related fuel usage is $n f G(y, e, s)$, which can then be written as $A G(y, e, s) / s d$. Combining this expression with in-flight fuel usage, given by 
$A F(e, s, d, \ell, v)$, total fuel usage can be written as

$$
\text { Total fuel usage }=A\left[F(e, s, d, \ell, v)+\frac{G(y, e, s)}{s d}\right] \equiv A H(e, s, d, \ell, v, y)
$$

where the $H(\cdot)$ function represents the bracketed term in the middle expression in (3), being equal to total fuel usage per ASM, inclusive of delay effects (the effects of $H$ 's arguments are shown).

Since $F$ and $G$ are both decreasing in fuel efficiency $e, H$ is decreasing as well $\left(H_{e}<0\right)$. The effects of load factor $\ell$ and fuel conservation $v$ in $F$ are also passed through to $H$, with $H_{\ell}>0$ and $H_{v}<0$. Since both $F$ and the ratio term $G / s d$ are decreasing in stage length $d$, $H$ is decreasing as well $\left(H_{d}<0\right)$. Finally, while the effect of seats $s$ on the ratio term in $(3)$ is ambiguous given $G_{s}>0$, this effect of $s$ on delay-related fuel usage may not be strong enough to offset the $s$ appearing in the ratio's denominator. As a result, the ratio is likely to decrease with $s$, and combined with the negative effect of $s$ via $F$, the overall fuel-usage effect of seats per aircraft is still likely to be negative $\left(H_{s}<0\right)$. Finally, since $G_{y}>0, H$ is increasing in delay per flight.

\subsection{Airline choices}

The goal of the empirical work is to estimate (3). However, some of variables in the model (in particular, $v$ ) are unobservable and others (in particular, e) pose measurement problems. To remedy these obstacles, it is useful to analyze the profit-maximizing choices of the airline, which allows $e$ and $v$ to be connected to more-easily measured factors.

To do so, let $p$ be the airline's "yield," or revenue per passenger mile. Then total revenue equals $A \ell z p$, recognizing that ASM times the load factor $(A \ell)$ equals revenue passenger miles ( $z$ is a factor that captures the cost of a high load factor; see the appendix). Profit is then equal to $A \ell z p$ minus fuel cost based on (1), with capital cost, labor cost, and the costs imposed by fuel-conservation effort $v$ also subtracted off.

Labor costs can be written as Aw, where $w$ is labor cost per ASM. The cost of fuelconservation effort per ASM is given by $K(v)$, with $K^{\prime}>0$, so that overall costs are $A K(v)$. 
Ignoring ground capital, capital cost consists of the annualized costs of aircraft, which are proportional to the purchase price per plane. The purchase price of a new aircraft will in turn depend on the size $s$ of the aircraft and its fuel efficiency $e$. In addition, because of the increasing technology content and overall complexity of aircraft, the cost of a new aircraft with particular characteristics will also rise over time (although generalized price inflation is ignored). Therefore, the annualized cost of an aircraft can be written as $C(e, s, t)$, where $t$ is the build year. Since larger and more fuel-efficient aircraft are more costly, as are aircraft built later in time, $C_{s}, C_{e}$, and $C_{t}$ are all positive. In addition, because of technological progress in engine design and the use of lighter composite materials, the cost of raising fuel efficiency has declined over time, making the cross-partial derivative $C_{e t}$ negative.

The capital cost component of airline costs equals $n C(e, s, t)$, where $n$ is again the number of aircraft. Using $A=n f s d$, this cost can be written as $A C(e, s, t) / s f d$. The expression $f d$ in the denominator equals annual miles flown per aircraft (flights per aircraft times stage length). This distance must be increasing in stage length since, with longer flights, an aircraft spends less time on the ground per day and thus flies more miles. ${ }^{6}$ Letting miles per aircraft be denoted $m(d) \equiv f d$, where $m^{\prime}>0$, capital cost can then be rewritten as $A C / \operatorname{sm}(d)$.

Bringing together the above elements along with fuel usage from (3), and letting $r$ denote the price of fuel, the annual profit of an airline making its initial aircraft choice at time $t$ is given by

$$
A\left[\ell z p-r H(e, s, d, \ell, v, y)-\frac{C(e, s, t)}{s m(d)}-K(v)-w\right] .
$$

The airline is portrayed as choosing the size $s$ of aircraft, their fuel efficiency $e$, the load factor $\ell$, and conservation effort $v$ to maximize profit in (4), taking $A$ and stage length $d$ as given. ${ }^{7}$ It is important to recognize that the choice of fuel efficiency is being made by the airline, not by the aircraft manufacturer, taking into account the effect of fuel efficiency on the purchase price. This view makes sense given that improvements in fuel efficiency are the result of both airline demands and technological progress.

The first-order conditions for choice of $e, s, \ell$ and $v$ are shown in the appendix. In general, these conditions yield solutions for the choice variables that each depends on all the parameters 
of the problem, which are $p, r, d, y$, and $t$. But as a simplifying approximation for purposes of motivating the empirical work, suppose that the function $H$ can be written as additively separable in its arguments, so that all of its cross partial derivatives equal zero. In addition, suppose that the $C$ function can be written as $C^{1}(e, t)+C^{2}(s)$, with $C_{e}^{1}, C_{t}^{1}, C_{s}^{2}>0$ and $C_{e t}^{1}<0 .{ }^{8}$ Then, the parameter dependence of $e, s, \ell$ and $v$ is simplified, as follows:

$$
\begin{aligned}
& +++++\quad+\quad+ \\
& e=e(r, t, d) ; \quad s=s(r, t, d) ; \quad \ell=\ell(p) ; \quad v=v(r)
\end{aligned}
$$

Thus, the optimal fuel-conservation effort $v$ depends only on the fuel price, increasing with $r$. The optimal load factor $\ell$ depends only on the yield, increasing with $p$. The optimal $e$ and $s$ are both increasing in $r$ and $t$, indicating that a higher fuel price leads to larger and more fuel-efficient aircraft, and that aircraft whose characteristics are chosen later in time are also larger and more fuel efficient. ${ }^{9}$ A longer stage length also raises $s$ and $e .^{10}$

As mentioned above, measurement problems involving fuel efficiency and fuel-conservation effort motivate this airline-choice analysis, which allows $e$ and $v$ to be replaced by other variables $(t$ and $r$ ) that are more easily measured. Thus, substituting for $e$ and $v$ using (5), total fuel usage can be written

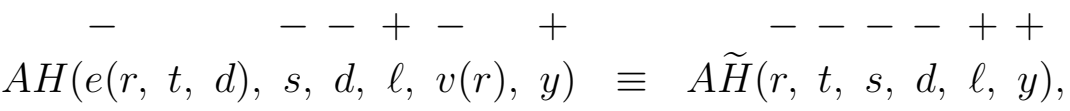

$$
\begin{aligned}
& +++
\end{aligned}
$$

so that the effects of $e$ and $v$ are now captured by $r$ and $t$ in a new function $\widetilde{H}$. Note that since $s$ and $\ell$ are observable, there is no need to substitute the solutions $s(r, t, d)$ and $\ell(p)$ in reaching (6).

The expression in (6) gives fuel usage for an airline that has just deployed the brand-new aircraft it has purchased. Since the effects of $s, \ell$, and $y$ are passed through from $H$ to $\widetilde{H}$, total fuel usage in (6) is decreasing in the size $s$ of these aircraft and increasing in $\ell$ and flight delay $y$. Moreover, since a higher fuel price $r$ raises both $e$ and $v$, and since $H$ is decreasing 
in $e$ and $v$, a higher fuel price naturally reduces fuel usage. Similarly, since a higher $t$ raises $e$, thus reducing $H$, fuel usage for an airline deploying new aircraft later in time is lower. Since the direct effect of stage length $d$ on fuel usage (via $H$ ) is negative, while $d$ 's indirect effect raises $e$ and thus also decreases $H$, the combined effect of a higher stage length is negative.

Now change the focus from an airline deploying brand-new planes to a carrier that is observed years after its initial aircraft purchases. Suppose these purchases were made in year $t_{0}$ when the fuel price was $r_{0}$. Letting $r$ continue to denote the current fuel price, and assuming that $d, \ell$ and $y$ are unchanged since $t_{0}$, current fuel usage is given by

$$
A H\left(e\left(r_{0}, t_{0}, d\right), s, d, \ell, v(r), y\right) \equiv A \widehat{H}\left(r_{0}, r, t_{0}, s, d, \ell, y\right)
$$

Note in (7) that fuel conservation effort, which can be adjusted over time (unlike aircraft characteristics), depends on the current fuel price $r$, while fuel efficiency $e$ depends on the fuel price $r_{0}$ in the initial year and on the index $t_{0}$ of that year (the effects of both fuel prices are negative).

\section{Empirical implementation}

The empirical model estimated in the next section of the paper is built upon (7). In the model, an airline's total fuel usage depends on overall capacity $A$, aircraft size $s$, stage length $d$, load factor $\ell$, flight delays $y$, the current fuel price $r$, and the "vintage" (construction date $t_{0}$ ) of its aircraft. While (7) includes the initial fuel price $r_{0}$, that price depends on $t_{0}$ and is thus captured by the vintage variable.

While the model has been developed assuming that $s, d, \ell$, and $t_{0}$ are uniform within an airline, these variables are heterogeneous in reality. Therefore, the empirical model uses average values of the variables, which are denoted AVG_SEATS, AVG_STAGELN, AVG_LOADFC, AVG_VINTG. The delay variable $y$ is represented by PCT_DELAY, which equals the percentage of flights with delays of more than 15 minutes, and the current fuel price is denoted FUELPR. As mentioned above, the airline's capacity $A$ is actually measured by available ton

miles (ATM, which captures passenger, freight and mail capacity) rather that ASM, even though the model was developed using ASM for concreteness. Accordingly, the average load 
factor is measured in terms of weight rather than passengers, with AVGLOADF equal to revenue ton miles (RTM) divided by available ton miles (ATM). However, since seats remains a good indicator of combined passenger and freight capacity, AVG_SEATS is used as the aircraft

size measure. AVG_STAGELN is computed by dividing the airline's annual flight miles by the number of departures, and AVG_VINTG is a weighted average of aircraft vintages, with weights equal to aircraft seats.

To derive the estimating equation, let $\widehat{H}$ in $(7)$ be written as

$$
\begin{aligned}
\exp (\alpha+\beta \text { AVG_SEATS } & +\gamma \text { AVG_STAGELN }+\delta \text { AVG_LOADFC }+\theta \text { AVG_VINTG }+ \\
& +\eta \text { PCT_DELAY }+\phi \text { FUELPR }+u)
\end{aligned}
$$

where $u$ is an error term. Multiplying (8) by $A=\mathrm{ATM}$, fuel usage equals $A \widehat{H}=\operatorname{ATM} e^{B}$, where $B$ is the expression following exp in (8). Taking logs then yields

$$
\begin{aligned}
& \ln (\text { FUEL_USE })=\alpha+\nu \ln (\text { ATM })+\beta \text { AVG_SEATS }+\gamma \text { AVG_STAGELN }+ \\
& \delta \text { AVG_LOADFC }+\theta \text { AVG_VINTG }+\eta \text { PCT_DELAY }+\phi \text { FUELPR }+u .
\end{aligned}
$$

Note that, while the $\nu$ coefficient on $\ln (\mathrm{ATM})$ should equal one, the estimation allows the data to determine its value.

\section{Data and Empirical Results}

\subsection{Data sources and summary statistics}

The FUEL_USE variable is drawn from the Air Carrier Financial Statistics (Schedule P12(a)) provided by the DOT's Bureau of Transportation Statistics (BTS). ${ }^{11}$ AVG_SEATS, AVG_STAGELN, AVG_LOADFC, and AVG_VINTG are computed using the BTS T2 and B43 datasets. ${ }^{12}$ PCT_DELAY comes from the BTS On-Time Performance data, and FUELPR uses average annual spot price data from the US Energy Information Administration. ${ }^{13}$

The means of the variables in the empirical model, computed at the airline level, are shown in Table 1, along with the number of years of data available for each airline. The data cover 
16 airlines, although 8 of these carriers are not represented for all 21 years of the 1995-2015 sample period due to mergers (AirTran, America West, Continental, Northwest, US Airways) or nonexistence early in the sample period (Allegiant, JetBlue, Virgin). Data for the delay variable is even more restricted due to unevenness of reporting, as seen in the column showing the number of years of available delay data.

ATM is naturally largest for the three big carriers, American, United and Delta, and FUEL_USE naturally matches this pattern, although its values are not shown. Table 1 instead presents fuel use per ATM, a variable that is not used in the regressions but shows interesting variation. AirTran, Spirit and Allegiant have the largest values, while the big three network carriers have lower values, as do Hawaiian and Virgin. AVG_SEATS varies across carriers in expected fashion, with Southwest and Frontier (both LCCs) showing the smallest values and Hawaiian along with the large network carriers operating the biggest planes. AVG_STAGELN shows similar variation, although the big airlines are joined by JetBlue and Virgin among carriers with the longest stage lengths. AVG_LOADFC, which is weight-based and not equal to the usual percentage of seats filled, shows substantial variation, with Allegiant and Spirit showing the highest values. AVG_VINTG, which is expressed in fractional years, does not vary much across most of the carriers, although the relatively young fleets of JetBlue and Virgin are exceptions. Recall that this vintage variable is year-specific, with the average vintage of an airline's planes changing across years as aircraft are added and retired. PCT_DELAY is above $20 \%$ for most carriers, although Hawaiian, Southwest and Virgin show lower values.

\subsection{Basic Results}

The basic regression results are shown in the first two columns of Table 2, with t-statistics based on robust standard errors. ${ }^{14}$ Since the missing years of delay data seen in Table 1 reduce the sample size, two regressions are reported. PCT_DELAY is omitted from the first regression, which is based on 284 observations, while the delay variable is included in the second regression, which uses a smaller set of 217 observations.

The coefficient estimates strongly support the predictions of the conceptual framework, with all coefficients showing the expected signs and statistical significance. In the first regression, an airline's fuel usage is almost exactly proportional to its available ton miles, with the 
coefficient of $\ln (\mathrm{ATM})$ very close to 1 . Holding $\ln (\mathrm{ATM})$ constant, $\ln (\mathrm{FUEL}$ _USE) is decreasing in AVG_SEATS, showing that fuel usage per available ton mile is lower with larger aircraft. The negative coefficient of AVG_STAGELN shows that fuel usage per ATM is decreasing in stage length, with longer flights raising fuel efficiency. An increase in AVG_LOADFC raises fuel usage per ATM, reflecting the greater weight carried as load factor rises. When AVG_VINTG increases, with the airline's planes built in later years, fuel usage falls, reflecting the influence of continuing technological improvements in raising aircraft fuel efficiency. A higher fuel price also reduces fuel usage, with airlines evidently expending more effort conserving fuel as FUELPR rises. The coefficients capturing these effects are all statistically significant at the $1 \%$ level.

The second regression in Table 1 adds PCT_DELAY to set of covariates, which reduces the sample size from 284 to 217 observations. This addition leads to only modest changes in the sizes of coefficients of the previous variables, with their $1 \%$ significance levels also unaffected. The coefficient of PCT_DELAY is positive, as expected, indicating that flight delays raise fuel consumption. The coefficient, however, is less precisely estimated than the others in the regression, being significant only at the $10 \%$ level. $^{15}$

Beyond these qualitative results, the coefficient estimates reveal the quantitative impact on fuel usage from changes in the explanatory variables. The unitary coefficient of $\ln (\mathrm{ATM})$ (which is an elasticity) shows that a $1 \%$ increase in ATM raises fuel usage by $1 \%$. Alternatively, suppose that average aircraft size increases by 10 seats, which corresponds to Southwest (136 seats) switching to Continental-size (146 seats) planes (see Table 1). Using the AVG_SEATS coefficient from the second regression, this shift would change $\ln (\mathrm{FUEL}$ USE) by $10 \times(-0.00201)=-0.02$, which translates to a $2 \%$ reduction in FUEL_USE. If Southwest instead switched to American-size planes (163 seats) while keeping ATM fixed, the fuel reduction would be almost three times as great, somewhat less than $6 \%$.

Next, suppose that stage length increases by 100 miles (Allegiant's 944-mile stage length would rise to Delta's 1040-mile length, holding ATM fixed). From Table 3, the effect on $\ln ($ FUEL_USE) would again be $-0.02=100 \times(-0.000205)$, for a reduction of $2 \%$ in usage, holding ATM fixed. If Allegiant instead had American's 1229 mile stage length, its fuel use 
per ATM would be almost $6 \%$ lower.

A 5 percentage point increase in an airline's load factor (a gain of 0.05 in AVG_LOADFC) would change $\ln \left(\mathrm{FUEL} \_U S E\right)$ by $0.082=0.05 \times 1.637$, for an $8.2 \%$ increase in usage, holding ATM fixed. While this effect seems substantial, further results presented below show that it is not due to omitted factors. Next, suppose that the average vintage of a carrier's aircraft increases by 3 years (American's 1993 vintage would rise to Southwest's 1996 vintage). The change in $\ln ($ FUEL_USE) would be $3 \times(-0.00752)=-0.022$, for a $2.2 \%$ reduction in usage. If American's average vintage were instead to match JetBlue's 2004 vintage (for a change of 11 years), the gain would be almost four times larger, for a reduction in fuel usage of $8.2 \%$.

If the percentage of delayed flights were to fall by three points (if Alaska's 0.22 delay share were to match Southwest's 0.19 share), then $\ln ($ FUEL_USE) would change by $0.03 \times(-0.296)=$ .009 , for almost a $1 \%$ reduction in usage. Finally, suppose that the price per gallon of jet fuel were to rise by $\$ 0.25$ from its sample-average value of $\$ 1.56$. The result would be a $-0.013=0.25 \times(-0.0562)$ change in $\ln ($ FUEL_USE), or a $1.3 \%$ reduction in usage.

Note that the carbon emissions of the airline, which are proportional to fuel usage, show the same percentage changes as usage itself. Table 3 list all the impacts that have just been derived.

If an appropriate emissions charge per gallon of fuel were imposed, the increase in the effective fuel price would be somewhat larger than the previous $\$ 0.25$ value. For use in deriving the appropriate charge, EPA conversion factors show that burning a gallon of jet fuel produces $9.75 \mathrm{~kg}$ of $\mathrm{CO}_{2} \cdot{ }^{16}$ Using a standard value of $\$ 40$ per metric ton (or $\$ 0.04 / \mathrm{kg}$ ) for the environmental damage from $\mathrm{CO}_{2}$ emissions, ${ }^{17}$ the required charge would be $9.75 \mathrm{~kg} / \mathrm{gallon}$ $\times \$ 0.04 / \mathrm{kg}=\$ 0.39 /$ gallon. This increase in the charge-inclusive fuel price would lead to a $0.39 \times(-0.0562)=-0.22$ change in $\ln ($ FUEL_USE), or a $2.2 \%$ reduction in usage and thus carbon emissions. For 2015, when total fuel usage for the airlines in the sample was 13.7 billion gallons, this $2.2 \%$ reduction amounts to 301 million gallons. The associated $\mathrm{CO}_{2}$ reduction is then $9.75 \mathrm{~kg} /$ gallon $\times 301$ million gallons $=2.93$ billion $\mathrm{kg}$, for an annual environmental gain of $\$ 0.04 / \mathrm{kg} \times 2.93$ billion $\mathrm{kg}=\$ 117$ million. Recall that, since the fuel price effect holds the airline's fleet and main operating characteristics constant, this gain is only short run in nature. 
The long run effect of an airline emissions charge would be larger.

Using a similar calculation, the environmental gain from the previous 3-point reduction in the average delay percentage can be computed. Since, from above, a reduction of this size reduces fuel use by $0.9 \%$, which equals a 0.41 share of the $2.2 \%$ reduction from the optimal emissions charge, the environmental gain is $0.41 \times \$ 117$ million, or $\$ 48$ million per year. This value can be added to the other passenger and airline cost savings from a reduction in delays.

\subsection{Adding a time trend and carrier fixed effects}

Two temporal effects underlie the basic regression results: higher vintages (later construction dates) for airline fleets, and an upward trend of fuel prices over most of the sample period. The correlations between time and each variable are both near 0.85, reflecting their strong temporal associations. It is interesting to ask whether a separate temporal force that operates independently of these two variables (reflecting, for example, growing concern about climate change) could exert an independent effect on airline operational practices. When a time-trend variable is added to the first regression of Table 2, its coefficient is significantly negative while the coefficients of the other variables maintain their signs and levels of statistical significance, although both the AVG_VINTG and FUELPR effects become smaller. However, when a time trend is added to the second regression, the coefficients of these two variables lose significance while the $t$-statistic of PCT_DELAY is also reduced (the trend's coefficient is again negative and significant). While this outcome only emerges in the presence of the delay variable, the overall performance of the regressions is impaired by the inclusion of a time trend. Since existence of a separate time force that affects fuel usage independently of the explanatory variables themselves is open to question, the basic model in the first two columns of Table 1 is preferred.

While the regression covariates capture the principal differences across carriers in fleet and operational characteristics, unobservable carrier-specific elements could still affect fuel usage. These factors can be captured by airline fixed effects, and the impact of including such carrier dummy variables is shown in the third and fourth columns of Table 2, which continue onto a second page (American is the omitted carrier). In the model without PCT_DELAY, shown in column 3, the main impact of carrier fixed effects is to cut the AVG_SEATS coefficient in half and to almost double the AVG_STAGELN coefficient. The coefficient of AVG_LOADFC 
changes little, showing that the seemingly large load-factor effect in the basic regression is not somehow a result unobserved carrier characteristics. In addition, the impact of FUELPR on fuel usage is less strong in the presence of fixed effects. However, the central qualitative conclusions of the basic model are preserved, showing that within-carrier variation of the covariates across time is strong enough to allow the previous connections between fuel usage and airline fleet and operational characteristics to be manifested.

The fixed-effects coefficients themselves provide a picture of airline fuel efficiency, controlling for carrier characteristics. Thus, unlike the fuel usage per ATM values in Table 1, the coefficients adjust for differences in fleet and operating characteristics. Recalling that American is the omitted carrier, the results in column 3 show that, among the large carriers, United and Continental match(ed) American's fuel efficiency, holding airline characteristics constant (their dummy coefficients are not significantly different from zero). In other words, if United's values of the other covariates were to match American's, the fuel usage of the two airlines would be close. On the other hand, Delta's coefficient shows that its fuel use would be $7 \%$ below American's, other things equal, with US Airways and Southwest showing similar 9\% differences and Northwest having an even-larger gap of $21 \% .{ }^{18}$ These differences are noteworthy, and it difficult to speculate about their sources. ${ }^{19}$

When PCT_DELAY is added to the regression, the number of observations drops as before, with the representation of four carriers (AirTran, Allegiant, Spirit, and Virgin) greatly reduced or eliminated. As can be seen in the fourth column of Table 2, the changes in the coefficients of AVG_SEATS and AVG_STAGELN relative to the basic model are amplified, and the fuel-price effect drops further. In addition, the standard error of the PCT_DELAY coefficient grows, making the coefficient insignificant even at the $10 \%$ level. While the estimated fixed effects for most of the larger carriers are fairly stable under this change, other fixed effects (Southwest's for example) grow dramatically, suggesting substantial (and perhaps implausible) fuel-efficiency advantages over American. In addition, the divergence of the $\ln$ (ATM) coefficient from unity grows. Given these changes, the regression in column 4 should perhaps be viewed with caution, even though the coefficients of most of the main covariates remain quite stable. 


\section{Conclusion}

This paper has estimated a simple model of airline fuel usage, connecting usage to a small set of crucial variables. The results are important because they allow an easy appraisal of how changes in an airline's fleet and operating characteristics, and in the fuel price it faces, affect fuel usage and level of carbon emissions, which is proportional to this usage. One message of the results, which reinforces the arguments of Morrell (2009), is that operation of larger aircraft is beneficial, reducing fuel usage and carbon emissions, holding an airline's overall capacity fixed. While an innate network characteristic such as stage length, also shown to be beneficial, cannot be altered easily, the paper identifies another operational change that lowers fuel usage and emissions and can be achieved by public policy: a reduction in flight delays. The paper thus suggests that policies for reducing airport congestion (such as peakhour congestion pricing) have benefits that go beyond the recognized savings in passenger time costs. For example, the environmental benefits from a hypothetical 3-point reduction in the average delay percentage amount to $\$ 48$ million per year, a value that can be added to the other passenger and airline gains from fewer delays. Airport congestion pricing or other policies for improving the functioning of the air transport system can thus produce environmental benefits.

By quantifying the impact of fuel prices on airline fuel usage, the paper also allows quantification of the emissions reduction from imposing an optimal emissions charge, which raises the effective fuel price. This reduction, equal to $2.2 \%$ in the basic regression (for an annual environmental gain of $\$ 117$ million), represents only the short-run effect from fuel-conserving operational practices, holding aircraft fuel efficiency and size fixed. The long run adjustments to such a charge would include a faster shift toward fuel-efficient aircraft as well as a likely increase in aircraft sizes. Thus, while the $2.2 \%$ short-run effect is itself appreciable in size, the long-run impact of emissions charges will be higher. 


\section{Appendix}

Using (4), the first-order condition for choice of $e$ reduces to

$$
-\operatorname{sm}(d) r F_{e}=C_{e}
$$

This condition says that the fuel-cost savings per seat mile from an increase in $e\left(-r F_{e}\right)$ times seat miles per aircraft $(s m(d))$ equals the $e$-induced increase in the aircraft purchase price. The first-order condition for choice of $s$ reduces to

$$
-s m(d) r F_{s}=C_{s}-C / s
$$

The left-hand side of $(3)$ is the fuel-cost savings per seat mile from an increase in $s\left(-r F_{s}\right)$ times seat miles per aircraft. This gain is set equal to the cost of a higher $s$, which equals increase in the cost per aircraft $\left(C_{s}\right)$ minus the cost saving from needing fewer aircraft $(-C / s)$, a consequence of their larger size. ${ }^{20}$

The $z$ factor in revenue $A \ell z p$ captures forces that reduce revenue at a high load factor, such as costs from overbooking ( $z$ is function of $\ell$, with $z^{\prime}(\ell)<0$ when $\ell$ is high). The first-order conditions for $\ell$ and $v$ are

$$
\begin{aligned}
p\left(z+\ell z^{\prime}\right) & =r F_{\ell} \\
-r F_{v} & =K^{\prime} .
\end{aligned}
$$

The first condition says that the revenue gain from a higher $\ell$ equals the cost in terms of higher fuel usage $\left(r F_{\ell}\right)$. The second condition says that the reduction in fuel cost from higher conservation effort $\left(-r F_{v}\right)$ equals the cost of the extra effort $\left(K^{\prime}\right)$. The second-order conditions for the maximization problem are assumed to hold.

Under the assumptions on $H$ and $C$ stated in the text, total differentiation of $(a 1)-(a 4)$ yields the functional dependencies stated in the text $(e(r, t, d), s(r, t, d), \ell(p), v(r))$ and the signs of the corresponding derivatives. 
Table 1: Variable Means

\begin{tabular}{|c|c|c|c|c|c|c|c|c|c|}
\hline Airline & ata yrs & FUEL_USE/ATM* & $\mathrm{ATM}^{\dagger}$ & AVG_SEATS & AVG_STAGELN & AVG_LOADFC & AVG_VINTG & Delay yrs & PCT_DELAY \\
\hline AirTran & 15 & 0.0804 & 3174.52 & 131.00 & 643.41 & 0.63 & 1993.71 & 9 & 0.22 \\
\hline Alaska & 21 & 0.0582 & 5906.62 & 141.93 & 930.44 & 0.59 & 1996.11 & 21 & 0.22 \\
\hline Allegiant & 12 & 0.0719 & 1370.68 & 151.73 & 944.11 & 0.74 & 1990.26 & 0 & - \\
\hline America West & 12 & 0.0597 & 6703.35 & 140.27 & 904.45 & 0.59 & 1990.50 & 11 & 0.25 \\
\hline American & 21 & 0.0542 & 51321.24 & 163.42 & 1229.66 & 0.56 & 1993.17 & 21 & 0.23 \\
\hline Continental & 17 & 0.0652 & 21186.16 & 146.44 & 1261.44 & 0.67 & 1993.83 & 17 & 0.22 \\
\hline Delta & 21 & 0.0562 & 46102.08 & 171.96 & 1040.51 & 0.59 & 1992.25 & 21 & 0.21 \\
\hline Frontier & 21 & 0.0461 & 3115.99 & 133.54 & 854.72 & 0.45 & 1996.82 & 10 & 0.22 \\
\hline Hawaiian & 21 & 0.0520 & 3002.51 & 203.58 & 587.08 & 0.57 & 1993.65 & 12 & 0.07 \\
\hline JetBlue & 16 & 0.0577 & 6851.78 & 145.04 & 1123.76 & 0.70 & 2004.05 & 13 & 0.24 \\
\hline Northwest & 15 & 0.0607 & 29289.38 & 159.18 & 944.26 & 0.63 & 1983.96 & 15 & 0.23 \\
\hline Southwest & 21 & 0.0615 & 21387.02 & 136.36 & 576.96 & 0.57 & 1996.01 & 21 & 0.19 \\
\hline Spirit & 21 & 0.0767 & 1476.68 & 148.13 & 917.29 & 0.76 & 1992.61 & 1 & 0.31 \\
\hline United & 21 & 0.0532 & 49436.27 & 179.07 & 1353.55 & 0.60 & 1993.92 & 21 & 0.23 \\
\hline US Airways & 20 & 0.0593 & 18010.70 & 142.64 & 796.97 & 0.57 & 1993.67 & 20 & 0.21 \\
\hline Virgin & 9 & 0.0499 & 2322.08 & 141.32 & 1461.83 & 0.60 & 2007.91 & 4 & 0.18 \\
\hline
\end{tabular}

*In gallons per ton mile

$\dagger$ In millions of ton miles 
Table 2: Regression Results

\begin{tabular}{|c|c|c|c|c|}
\hline & $(1)$ & $(2)$ & $(3)$ & (4) \\
\hline VARIABLES & $\ln \left(\mathrm{FUEL} \_\mathrm{USE}\right)$ & $\ln ($ FUEL_USE) & $\ln ($ FUEL_USE) & $\ln \left(\mathrm{FUEL} \_\mathrm{USE}\right)$ \\
\hline $\ln (\mathrm{ATM})$ & $\begin{array}{c}1.006^{* *} \\
(185.9)\end{array}$ & $\begin{array}{c}1.019^{* *} \\
(107.8)\end{array}$ & $\begin{array}{c}0.988^{* *} \\
(54.76)\end{array}$ & $\begin{array}{c}0.927^{* *} \\
(36.90)\end{array}$ \\
\hline AVG_SEATS & $\begin{array}{c}-0.00250^{* *} \\
(-5.640)\end{array}$ & $\begin{array}{c}-0.00201^{* *} \\
(-3.056)\end{array}$ & $\begin{array}{c}-0.00124^{* *} \\
(-2.690)\end{array}$ & $\begin{array}{c}-0.000622^{*} \\
(-2.195)\end{array}$ \\
\hline AVG_STAGELN & $\begin{array}{c}-0.000163^{* *} \\
(-6.266)\end{array}$ & $\begin{array}{c}-0.000205^{* *} \\
(-5.195)\end{array}$ & $\begin{array}{c}-0.000291^{* *} \\
(-5.665)\end{array}$ & $\begin{array}{c}-0.000393^{* *} \\
(-5.848)\end{array}$ \\
\hline AVG_LOADFC & $\begin{array}{c}1.606^{* *} \\
(16.22)\end{array}$ & $\begin{array}{c}1.637^{* *} \\
(8.389)\end{array}$ & $\begin{array}{c}1.563^{* *} \\
(12.56)\end{array}$ & $\begin{array}{c}1.528^{* *} \\
(10.30)\end{array}$ \\
\hline AVG_VINTG & $\begin{array}{c}-0.0103^{* *} \\
(-8.868)\end{array}$ & $\begin{array}{c}-0.00752^{* *} \\
(-4.278)\end{array}$ & $\begin{array}{c}-0.0113^{* *} \\
(-8.273)\end{array}$ & $\begin{array}{c}-0.00874^{* *} \\
(-4.526)\end{array}$ \\
\hline FUELPR & $\begin{array}{c}-0.0483^{* *} \\
(-5.644)\end{array}$ & $\begin{array}{c}-0.0562^{* *} \\
(-5.542)\end{array}$ & $\begin{array}{c}-0.0319 * * \\
(-3.767)\end{array}$ & $\begin{array}{c}-0.0202^{*} \\
(-2.302)\end{array}$ \\
\hline PCTDELAY & & $\begin{array}{l}0.296^{\dagger} \\
(1.808)\end{array}$ & & $\begin{array}{l}0.119 \\
(1.151)\end{array}$ \\
\hline AirTran & & & $\begin{array}{l}0.0370 \\
(0.538)\end{array}$ & $\begin{array}{l}-0.206^{*} \\
(-2.459)\end{array}$ \\
\hline Alaska & & & $\begin{array}{c}-0.0945^{\dagger} \\
(-1.889)\end{array}$ & $\begin{array}{c}-0.251^{* *} \\
(-4.022)\end{array}$ \\
\hline Allegiant & & & $\begin{array}{c}-0.161^{*} \\
(-2.118)\end{array}$ & \\
\hline America_West & & & $\begin{array}{c}-0.142^{* *} \\
(-3.584)\end{array}$ & $\begin{array}{c}-0.274^{* *} \\
(-5.255)\end{array}$ \\
\hline Continental & & & $\begin{array}{c}-0.0224 \\
(-0.877)\end{array}$ & $\begin{array}{c}-0.0574^{\dagger} \\
(-1.744)\end{array}$ \\
\hline Delta & & & $\begin{array}{c}-0.0705^{* *} \\
(-4.782)\end{array}$ & $\begin{array}{c}-0.0968^{* *} \\
(-5.560)\end{array}$ \\
\hline Frontier & & & $\begin{array}{c}-0.184^{*} \\
(-2.362)\end{array}$ & $\begin{array}{c}-0.397^{* *} \\
(-4.420)\end{array}$ \\
\hline Hawaiian & & & $\begin{array}{c}-0.258^{* *} \\
(-3.408)\end{array}$ & $\begin{array}{c}-0.532^{* *} \\
(-5.540)\end{array}$ \\
\hline JetBlue & & & $\begin{array}{l}-0.106^{*} \\
(-2.034)\end{array}$ & $\begin{array}{c}-0.221^{* *} \\
(-3.813)\end{array}$ \\
\hline
\end{tabular}

(continued) 
Table 2: Continued

\begin{tabular}{|c|c|c|c|c|}
\hline & (1) & $(2)$ & $(3)$ & $(4)$ \\
\hline VARIABLES & $l n \_$FUEL_USE & $l n \_F U E L \_U S E$ & $l n \_$FUEL_USE & $l n \_F U E L \_U S E$ \\
\hline Northwest & & & $\begin{array}{c}-0.209^{* *} \\
(-10.79)\end{array}$ & $\begin{array}{c}-0.238^{* *} \\
(-9.212)\end{array}$ \\
\hline Southwest & & & $\begin{array}{c}-0.0953^{*} \\
(-2.186)\end{array}$ & $\begin{array}{c}-0.205^{* *} \\
(-3.856)\end{array}$ \\
\hline Spirit & & & $\begin{array}{l}-0.148^{\dagger} \\
(-1.904)\end{array}$ & $\begin{array}{c}-0.443^{* *} \\
(-5.028)\end{array}$ \\
\hline United & & & $\begin{array}{c}-0.0173 \\
(-1.004)\end{array}$ & $\begin{array}{c}-0.0177 \\
(-0.929)\end{array}$ \\
\hline US_Airways & & & $\begin{array}{c}-0.0894^{* *} \\
(-2.758)\end{array}$ & $\begin{array}{c}-0.184^{* *} \\
(-4.582)\end{array}$ \\
\hline Virgin & & & $\begin{array}{l}0.0584 \\
(0.871)\end{array}$ & $\begin{array}{l}-0.118 \\
(-1.459)\end{array}$ \\
\hline Constant & $\begin{array}{c}17.30^{* *} \\
(7.450)\end{array}$ & $\begin{array}{c}11.37^{* *} \\
(3.184)\end{array}$ & $\begin{array}{c}19.61^{* *} \\
(7.706)\end{array}$ & $\begin{array}{c}15.52^{* *} \\
(4.149)\end{array}$ \\
\hline $\begin{array}{l}\text { Observations } \\
R^{2}\end{array}$ & $\begin{array}{c}284 \\
0.995\end{array}$ & $\begin{array}{c}217 \\
0.993\end{array}$ & $\begin{array}{c}284 \\
0.997\end{array}$ & $\begin{array}{c}217 \\
0.997\end{array}$ \\
\hline
\end{tabular}


Table 3: Quantitative Impacts

\begin{tabular}{ll}
\hline \hline Change in variable & Impact on fuel usage and emissions \\
\hline Available ton miles rises by $1 \%$ & $1 \%$ increase \\
Seats per aircraft rises by 10 & $2 \%$ decrease \\
Stage length rises by 100 miles & $2 \%$ decrease \\
Load factor rises by 5 percentage points & $8.2 \%$ increase \\
Aircraft vintage becomes younger by 3 years & $2.2 \%$ decrease \\
Delay fraction falls by 3 percentage points & $0.9 \%$ decrease \\
Fuel price rises by $\$ 0.25 /$ gallon & $1.3 \%$ decrease \\
Optimal emissions charge ( $\$ 0.39 /$ gallon) imposed & $2.2 \%$ decrease \\
\hline \hline
\end{tabular}




\section{References}

Albers, S., Buhne, J.-A., Peters, H., 2009. Will the EU-ETS instigate airline network reconfigurations? Journal of Air Transport Management 15, 1-6.

Brueckner, J.K., Zhang, A., 2010. Airline emission charges: Effects on airfares, service quality, and aircraft design. Transportation Research Part B 44, 960-971.

CzERny, A.I., 2015. The role of capital costs for airline responses to emission charges. Journal of Transport Economics and Policy 49, 475-495.

Givoni, M., Rietveld, P., 2009. Choice of aircraft size-Explanations and implications. Transportation Research Part A 43, 500-510.

Hao, L., Ryerson, M., Kang, L., Hansen, M., 2016. Estimating fuel burn impacts of taxi-out delay with implications for gate-hold benefits. Transportation Research Part C, in press.

Hao, L., Hansen, M., Ryerson, M., 2016. Fueling for contingencies: The hidden cost of unpredictability in the air transportation system. Transportation Research Part D, in press.

Interagency Working Group on Social Cost of Carbon, United States GovERnment, 2015. Technical Support Document: Technical Update of the Social Cost of Carbon for Regulatory Impact Analysis Under Executive Order 12866. US Government Printing Office, Washington D.C.

Kwan, I., Rutherford, D., 2015. Assessment of U.S. domestic airline fuel efficiency since 2010. Transportation Research Record 2501, 1-8.

Lee, J.J., Lukachko, S.P., Waitz, I.A., Schafer, A., 2001. Historical and future trends in aircraft performance, cost, and emissions. Annual Review of Energy Environment $26,167-200$.

Lee, J.J., Lukachko, S.P., Waitz, I.A., 2004. Aircraft and energy use. Encyclopedia of Energy, Vol. 1. Elsevier, Amsterdam.

Miyoshi, C., Mason, K.J.,, 2009. The carbon emissions of selected airlines and aircraft types in three geographic markets. Journal of Air Transport Management 15, 138-147.

MoOney, C., 2016. U.N. panel proposes historic cuts to aircraft emissions-but environmentalists say it's not enough. Washington Post, Feb. 8. 
Morrell, P., 2009. The potential for European aviation $\mathrm{CO}_{2}$ emissions reduction through the use of larger jet aircraft. Journal of Air Transport Management 15, 151-157.

Mouawad, J., Davenport, C., 2016. U.N. agency proposes limits on airlines' carbon emissions. New York Times, Feb. 9.

PAI, V., 2010. On the factors that affect airline flight frequency and aircraft size. Journal of Air Transport Management 16, 169-177.

Ryerson, M.S., Hansen, M., 2013. Capturing the impact of fuel price on jet aircraft operating costs with Leontief technology and econometric models. Transportation Research Part C 33, 282-296.

Ryerson, M.S., Hansen, M., Hao, L., Seelhorts, M., 2015. Landing on empty: Estimating the benefits from reducing fuel uplift in US civil aviation. Environmental Research Letters 10, 094002.

Scheelhasse, J.D. Grimme, W.G., 2007. Emissions trading for international aviation-An estimation of the economic impact on selected European airlines, Journal of Air Transport Management 13, 253-263.

Swan, W.M., Adler, N., 2006. Aircraft trip cost parameters: A function of stage length and capacity. Transportation Research Part E 42, 105-115.

Zou, B., Elke, M., Hansen, M., Kafle, N., 2014. Evaluating air carrier fuel efficiency in the US airline industry. Transportation Research Part A 59, 306-330. 


\section{Footnotes}

*We thank Achim Czerny, Alex Luttman, Kevin Roth, Megan Ryerson, Ethan Singer, and Bo Zou for comments, although any errors or shortcomings in the paper are our responsibility.

${ }^{1}$ See Czerny (2015) for an extension of their model.

${ }^{2}$ In addition, the goal of Zou et al. (2014) is to estimate a stochastic-frontier model with the goal of appraising the airline technical efficiency. The present regressions, by contrast, are purely descriptive.

${ }^{3}$ For passenger aircraft, combined passenger and freight capacity is roughly proportional to seats, making this distinction inessential.

${ }^{4}$ For other papers with information on the connection between general operating costs and aircraft size, stage length and other variables, see Lee et al. (2001), Kwan and Rutherford (2015), Ryerson and Hansen (2013), and Swan and Adler (2006).

${ }^{5}$ While, in years past, congestion often kept planes in the air longer as they circled waiting to land, the use of "ground holds" at origin airports appears to have reduced this source of fuel usage. Delays can also result from mechanical problems and late-arriving crew members, sources that have no fuel-usage impact.

${ }^{6}$ Let $T$ denote operating hours per aircraft per year. Also, let the time per flight as a function of stage length be written as $\rho+\tau d$, where $\rho$ captures the fixed ground time. Then, $f(\rho+$ $\tau d)=T$ must hold, so that $f=T /(\rho+\tau d)$. As a result, annual miles per aircraft equals $f d=T d /(\rho+\tau d) \equiv m(d)$, and differentiation establishes $m^{\prime}(d)>0$.

${ }^{7}$ In Brueckner and Zhang's (2010) related analysis of airline profit maximization, the carrier's total traffic (analogous to $A$ ) was determined endogenously, not taken as given.

${ }^{8}$ These conditions would be satisfied, for example, if $C^{1}(e, t)$ takes the form $\kappa e+\nu t-\lambda e t$, with $\lambda$ small enough that $C_{e}^{1}=\kappa-\lambda t>0$ and $C_{t}^{1}=\nu-\lambda e>0$ both hold over the relevant range of $e$ and $t$ values (note that $C_{e t}^{1}=-\lambda<0$ ).

${ }^{9}$ This year effect can be seen in diagrams presented by Lee et al. (2004).

${ }^{10}$ See Givoni and Rietveld (2009) and Pai (2009) for empirical studies of the determinants of 
aircraft size.

${ }^{11}$ The link is www.transtats.bts.gov/DL_SelectFields.asp?Table_ID=294\&DB_Short_ Name=Air $\% 20$ Carrier\%20Financial.

${ }^{12}$ The links are www.transtats.bts.gov/DL_SelectFields.asp?Table_ID=254\&DB_Short_ Name=Air\%20Carrier\%20Summary and www.transtats.bts.gov/DL_SelectFields.asp? Table_ID=314.

${ }^{13}$ The links are www.transtats.bts.gov/DL_SelectFields.asp?Table_ID=236 and www.eia.gov/dnav/pet/pet_pri_spt_s1_d.htm.

${ }^{14}$ While clustering of the coefficient standard errors by carrier might seem appropriate given the possibility of within-carrier error correlation over time, the fact that four of the big carriers surviving until the end of period had changed their natures during it via mergers calls into question a simple correlation scenario (the pre- and post-merger carriers were presumably different entities). Even despite this consideration, the number of carrier-based clusters would be too small for proper implemenation of the method.

${ }^{15}$ When regular, as opposed to robust, standard errors are used, the significance level rises to $1 \%$.

${ }^{16}$ The link is www.epa.gov/sites/production/files/2015-07/documents/emissionfactors2014.pdf.

${ }^{17}$ See Interagency Working Group on Social Cost of Carbon, United States Government (2015) (https://www.whitehouse.gov/sites/default/files/omb/inforeg/scc-tsd-finaljuly-2015.pdf) .

${ }^{18} \mathrm{As}$ is well known, dummy-variable coefficients closely approximate percentage changes in a semilog regression when they are reasonably close to zero, while modestly overstating these changes when they diverge from zero (as in the case of the Southwest coefficient). This point should be borne in mind when interpreting the results.

${ }^{19}$ To see the effect of adjustment for airline characteristics, note that Allegiant's high fuel usage per ATM in Table 1 is replaced by a negative fixed effect when controlling for the carrier's characteristics. Other similar differences can be seen by comparing the two tables.

${ }^{20}$ This condition ignores a possible constraint on $s$ related to stage length. In particular, 
since very long stage lengths are not feasible with small aircraft, a constraint of the form $s \geq q(d)$ should be imposed, where the increasing function $q(\cdot)$ gives the minimum aircraft size required for a stage length $d$. The first-order condition (a1) assumes that this constraint is not binding, but if the constraint were binding, $s$ would be replaced by $q(d)$. 